\title{
Uma Avaliação Experimental do Uso de um Framework Gamificado para a Disciplina Algoritmos e Equivalente
}

\author{
José Augusto de Sena Quaresma ${ }^{1}$, Marianne Kogut Eliasquevici ${ }^{2}$, Sandro Ronaldo \\ Bezerra Oliveira ${ }^{1,2}$
}

${ }^{1}$ Programa de Pós-Graduação em Criatividade e Inovação em Metodologias do Ensino

Superior (PPGCIMES) - Núcleo de Tecnologias Aplicadas ao Ensino e a Extensão

(NITAE ${ }^{2}$, Universidade Federal do Pará (UFPA) - Rua Augusto Corrêa, 01 - Guamá -

Belém - PA - Brasil

\begin{abstract}
2Programa de Pós-Graduação em Ciência da Computação (PPGCC) e Faculdade da Computação (FACOMP) - Instituto de Ciência Exatas e Naturais, Universidade Federal do Pará (UFPA) - Rua Augusto Corrêa, 01 - Guamá - Belém - PA - Brasil

augustoquaresma@ufpa.br, mariane@ufpa.br, srbo@ufpa.br
\end{abstract}

\begin{abstract}
This paper presents a way of evaluating and validating a gamified framework for the teaching and learning process of Algorithms. In the research we report the planning for the experiment, the SWOT matrix evaluation adapted to the practices worked in the classroom, the cases that occurred, the quantitative data generated by the gamification. The main contribution of the work is to inform that gamification promotes engagement and enables the teaching and learning of algorithms, from the use of a framework.

Resumo. Este artigo apresenta uma forma de avaliação e validação de um framework gamificado para o processo de ensino e aprendizado de Algoritmos. Na pesquisa relatamos o planejamento abordado para o experimento, a avaliação a partir da matriz SWOT adaptada para as práticas trabalhadas em sala de aula, os casos particulares que aconteceram, os dados quantitativos gerados pela gamificação. A principal contribuição do trabalho é informar que a gamificação promove engajamento $e$ possibilita o ensino e aprendizado de algoritmos, a partir do uso de um framework.
\end{abstract}

\section{Introdução}

A disciplina Algoritmos é apresentada aos alunos nos semestres iniciais dos cursos de Tecnologia da Informação (TI) e, consequentemente, estabelece a primeira interação dos discentes com o desenvolvimento de software. Possui o objetivo de desenvolver no aluno a capacidade de elaborar soluções lógicas mediante problemas genéricos em uma sequência de passos [Dias Júnior e Mercado, 2016]. Segundo o documento referente à formação dos cursos superiores em Computação [Sociedade Brasileira da Computação, 2017], tais competências e habilidades são bases para a formação dos futuros profissionais nas áreas de Tecnologia da Informação, com especial ênfase no eixo de desenvolvimento de software.

Sabe-se que a disciplina Algoritmos é importante para a formação dos novos profissionais, pois atua como subsídio na continuidade do curso. Dias Júnior e Mercado (2016) elencam alguns pontos abordados em vista às dificuldades na visão do aluno para o aprendizado da disciplina, como: conhecimento de lógica; dificuldade para entender o problema; e o conteúdo de estrutura de dados homogêneos. No entanto, é possível identificar o alto índice da redução de reprovação e evasão, com base nas revisões sistemáticas da literatura [Bosse e Gerosa, 2015; Marcussi et al., 2016; Ramos e Espadeiro, 2014] sobre artigos que propunham intervenções de ensino na disciplina.

Logo, a busca por abordagens didáticas e metodológicas que busquem facilitar o ensino de algoritmos por parte do professor, bem como o aprendizado por parte dos estudantes, é algo que precisa e vem sendo perseguido. Dentre estas, no decorrer das pesquisas para a realização do 
trabalho, identificou-se o uso e a defesa da gamificação na educação, que busca por um maior engajamento do estudante por meio da inserção de elementos de jogos no contexto diferente de jogos [Deterding, 2011]. Estudos defendem a proposta de se utilizar elementos de jogos para envolver os alunos para o estímulo ao seu aprendizado.

No contexto deste estudo, foram utilizadas algumas técnicas de desenvolvimento ágil como o DOJO, que, de acordo com Luz e Neto (2012), é uma atividade dinâmica e colaborativa inspirada em artes marciais, que segue uma disciplina em um ambiente de ensino seguro. Outra técnica adotada neste estudo foi o LAB (Laboratório de Programação [Elgrably e Oliveira, 2018; Santos e Oliveira, 2018]), onde no experimento a sala de aula foi organizada em duplas, e cada uma deveria resolver quatro desafios, que serão melhor detalhados no decorrer deste artigo. $\mathrm{O}$ desenvolvimento das atividades ocorreu segundo o modelo proposto no estudo de Quaresma et. al. (2018), no qual foi projetado um framework gamificado para o ensino e aprendizagem de Algoritmos, em específico o conteúdo de estrutura de dados homogêneos.

Desta forma, o principal objetivo desta pesquisa é relatar e discutir resultados obtidos na aplicação do framework gamificado (plano de ensino gamificado e planilha de gamificação com seus elementos), do conjunto de técnicas e do jogo no ensino da disciplina Algoritmos, em especial no conteúdo Estrutura de Dados Homogêneos. Com isso, foi definido um estudo de caso e aplicado em uma turma de graduação em Ciência da Computação para coletar os resultados e averiguar se o framework gamificado é uma boa abordagem para o ensino de Algoritmos. Assim, este trabalho busca propor uma forma para o ensino de Algoritmos em cursos de graduação em Tecnologia da Informação. Pode-se constatar que muitos são os nomes atribuídos para esta disciplina, como Introdução à Programação, Introdução à Ciência da Computação, Introdução à Programação de Computadores, Lógica de Programação, entre outras. Neste artigo será utilizado o nome Algoritmos ou equivalentes.

Esta pesquisa pode ser classificada como: uma pesquisa aplicada que tem como um dos objetivos gerar conhecimento e melhorar o entendimento a partir da gamificação voltada para o ensino de Algoritmos; é quantitativa, pois os dados e as informações foram armazenados e manuseados com o apoio de uma planilha eletrônica, onde estavam contidas todas as pontuações e bonificações de cada aluno em cada atividade realizada ou participação no processo; também é qualitativa, pois durante o planejamento houve um espaço destinado para coletar as opiniões, críticas e sugestões dos alunos (aula de feedback); é exploratória, pois foi desenvolvido um estudo de caso com o objetivo de ensinar o conteúdo de estrutura de dados homogêneos em uma sala de aula gamificada, onde, após a aplicação do experimento, os resultados foram analisados e discutidos entre os autores.

O artigo está organizado da seguinte maneira: a Seção 2 apresenta o planejamento do experimento; a Seção 3 relata a avaliação através dos os resultados quantitativos e qualitativos alcançados com um experimento; e a Seção 4 relata as conclusões e os trabalhos futuros.

\section{Planejamento do Experimento}

Durante o planejamento, com o intuito de nortear e analisar a execução do experimento, elaboramos a seguinte questão de pesquisa: $O$ uso de gamificação auxilia o engajamento da turma e colabora para a aprendizagem sobre o conteúdo de estrutura de dados homogêneos?

$\mathrm{O}$ experimento com o uso do framework gamificado foi a forma encontrada para avaliar e validar nossa proposta. O contexto de realização foi a disciplina Algoritmos, com carga horária de 60 horas, ofertada aos calouros no primeiro semestre letivo de 2018, pela Faculdade de Computação da Universidade Federal do Pará, em específico no período em que foi abordado o conteúdo de Estrutura de Dados Homogêneos (matriz e vetor).

O planejamento levou em consideração o plano de ensino e a planilha gamificada, segundo descrito em Quaresma et al. (2018). Os itens do planejamento são: cenário, personagens, desenvolvimento das aulas e o design da gamificação, descritos a seguir.

\subsection{Cenário}


A sala de aula é um dos núcleos mais importantes da gamificação, visto que foi nela o cenário do experimento e do jogo. As aulas ocorreram em um laboratório de informática, contendo: quadro magnético, destinado à explicação; projetor multimídia; e computadores para o docente e discentes. No dia da prova teórica os discentes foram para outro local, sem acesso à internet e sem o uso do computador. $\mathrm{Na}$ atividade $\mathrm{LAB}$, realizada em laboratório, foi disponibilizado um computador por dupla.

\subsection{Personagens}

Uma turma de graduação do curso de Bacharelado em Ciência da Computação da Universidade Federal do Pará contemplando 20 discentes, um monitor, a professora da disciplina e um estagiário, responsável pela gamificação.

\subsection{Desenvolvimento das Aulas}

Conforme o plano de ensino, o experimento contabilizou 8 aulas. A Aula 01 foi destinada a uma conversa inicial sobre gamificação, em que foi apresentado o plano de ensino, em formato de apresentação, contendo: a meta, as regras e os personagens da gamificação. Foram explicados, também, como os discentes ganhariam pontos e bonificariam, assim como o cronograma das aulas. Neste dia não foi atribuída pontuação aos discentes, apenas bonificação. Nas Aulas 02 e 03 foi adotada a abordagem teórica e prática (ATP) com o conteúdo estrutura de dados homogêneos. $\mathrm{Na}$ segunda aula foi trabalhado o conteúdo vetores e na terceira abordou-se sobre matrizes. A explicação estruturou-se da seguinte forma: o conceito, uma metáfora, a implementação na linguagem Pascal e, por fim, os discentes eram convidados a resolver questões referentes ao conteúdo. O discente recebia 25 pontos por resolução de desafio, com 4 desafios por dia, totalizando por dia 100 pontos, além disso ele poderia bonificar por comportamento.

Nas Aulas 04 e 05 foi realizada a aplicação da técnica do DOJO do tipo Randori, que é uma atividade realizada em pares em um ambiente seguro de programação. Os discentes tiveram um período inicial de 10 minutos para verificar e analisar a questão proposta. Após esse período, um discente assumia como primeiro piloto e depois de 7 minutos ocorria a troca por outro discente, até que todos os discentes participassem da atividade. A posição de copiloto era opcional, reservada para caso algum discente desejasse ajudar o piloto na codificação. Após 3 minutos do piloto codificando, a plateia podia interagir com ele, bem como o copiloto voluntariar-se para ajudar. Como material necessário, foram utilizados um computador e um projetor multimídia. No que tange à pontuação atribuída aos alunos na prática do DOJO Randori, seguiu-se os seguintes requisitos com as pontuações devidas: funcionalidade concluída, 20 pontos; uso do fluxo programar-testar, 30 pontos; narrar a programação, 100 pontos; nota geral para a questão desenvolvida pelos alunos, 50 pontos.

$\mathrm{Na}$ Aula 06 houve a prática do LAB com pareamento, técnica na qual os discentes foram divididos em duplas por meio de sorteio, para resolver 4 problemas computacionais a partir de soluções algorítmicas, do conteúdo estrutura de dados homogêneos. No início da prática as orientações necessárias para o bom desenvolvimento foram repassadas aos jogadores pelos seguintes personagens: master, mentora e scoreplay. Como regra estabelecida, foi proibido o acesso à internet, e permitido coaching. Por coaching, entenda-se dicas de como resolver a questão. O material utilizado foi um computador para cada dupla. Essa prática foi adaptada do framework proposto por Elgrably e Oliveira (2018). No que se refere à pontuação concedida pela prática do $\mathrm{LAB}$, pontuou-se pela tentativa, 20 pontos e pelo código desenvolvido 30 pontos, em um total de 4 questões, logo, 200 pontos pela prática em sala. Além disso, a lista de exercício para casa, a qual era para entregar via plataforma Moodle nesse mesmo dia, e continha 10 questões com 10 pontos cada, atribuído para o discente, caso ele tenha respondido corretamente. Portanto, o total atribuído pela prática LAB é de 300 pontos, 200 em sala e 100 via plataforma Moodle, lista de exercício.

Nas Aula 07 os discentes foram submetidos a uma atividade avaliativa visando verificar e analisar o conhecimento e o aprendizado adquirido: um teste teórico contendo 4 questões 
subjetivas, em que 2 questões versaram sobre vetor e 2 foram sobre matrizes. Em relação à pontuação atribuída pelo teste teórico, era concedido ao aluno a cada desafio 7,5 pontos pela tentativa e 67,5 pontos pelo código desenvolvido, em um total de 4 desafios, logo, 300 pontos pela atividade. Na Aula 08 os discentes respondiam a questionamentos em relação ao framework gamificado com o intuito de registrar feedbacks sobre a abordagem para o processo de ensino e aprendizagem. Para esse dia não foi atribuída pontuação, apenas bonificação.

\subsection{O Design da Gamificação}

A colaboração foi um dos elementos norteadores da proposta de gamificação, por compreender a necessidade de motivar os discentes da turma a uma prática cada vez mais presente no mercado de trabalho, qual seja, o trabalho em equipe. Neste estudo, como já mencionado, o objetivo era pontuar, bonificar e avaliar os conhecimentos adquiridos sobre o conteúdo Estrutura de Dados Homogêneos. Para isso, como já informado, foram utilizados os seguintes instrumentos: plano de ensino e planilha gamificada.

À medida que os discentes adquiriam pontuações, a planilha eletrônica disponibilizada gerava os avatares diários automáticos segundo o padrão estabelecido nas regras presentes no plano de ensino. No que tange à bonificação, o discente ganhava ou perdia por critérios estabelecidos, sendo que por dia o elemento bônus podia gerar até três estrelas.

Um dos instrumentos do feedback para os discentes sobre a gamificação foi a partir da disponibilização da planilha gamificada a partir da sala de aula virtual e apresentação dela no início de cada aula. A planilha permitia aos discentes visualizar o seu progresso dentro do conteúdo gamificado na disciplina.

\section{Avaliação}

Para avaliar o uso do framework de gamificação, utilizamos uma combinação das abordagens de cunho qualitativo e os quantitativos, conforme descrevemos a seguir. Para o segundo conjunto, adotou-se como instrumento de coleta a planilha gamificada.

\subsection{Discussão e Resultados Qualitativos}

Segundo Creswell (2007), os dados qualitativos vêm das percepções do pesquisador em relação ao que está observando. Os dados foram coletados: (i) por meio de anotações sobre as percepções do pesquisador responsável pela gamificação, durante a sala de aula e em uma roda de conversa envolvendo: o scoreplay, a mentora e o master; (ii) por meio de gravações de áudio, previamente aprovadas pelos envolvidos, realizada na aula de feedback sobre as opiniões dos discentes; e (iii) anotações na planilha gamificada sobre o cunho de bonificações e penalidades, bem como as informações sobre alterações no framework.

A avaliação das metodologias de ensino empregadas e da gamificação empreendida, tomou por base a matriz de análise SWOT dos resultados da aula de feedback. A matriz de análise SWOT (Strangths, Weaknesses, Oportunities, Threats), também conhecida como FOFA (Forças, Fraquezas, Oportunidades e Ameaças), tem como função, segundo [Baldner et al., 2012], "analisar e cruzar as forças da empresa e as oportunidades do mercado, as fraquezas da empresa e as ameaças do mercado". Essa forma de análise é adotada nas ciências sociais com o intuito de aprimorar o desenvolvimento estratégico e operacional da empresa, como podemos perceber na fala dos autores. Além disso, foi adotada com sucesso para avaliar e aprimorar uma abordagem gamificada para o ensino e aprendizagem de Análise de Pontos por Função [Santos e Oliveira, 2018]. Portanto, entendemos como uma boa forma de avaliar as práticas desenvolvidas em sala de aula.

Por estarmos em um ambiente de sala de aula, os autores do trabalho definiram a alteração do item ameaças para observações, com o intuito de aprimorar a nossa avaliação sobre o processo. Pois, durante o experimento, ao final de cada aula fazíamos uma roda de conversa direcionada à construção da nossa adaptação da matriz SWOT. Coletávamos relacionados a cada item os seguintes pontos: Pontos fortes, os elementos, as mecânicas e formas trabalhadas em sala que foram positivas para o processo de ensino e aprendizagem; Pontos fracos, o que não teve 
boa aceitação e por consequência foi prejudicial ao desempenho dos discentes; Melhorias, as oportunidades de mudanças para o uso futuro do framework gamificado; Observações, as anotações sobre possíveis mudanças no planejamento dentro de sala de aula. No Quadro 1 podemos observar a sistematização dos dados sobre a SWOT adaptada produzida após o primeiro dia de aula teórica e prática.

\section{Quadro 1. Matriz SWOT adaptada: ATP primeiro dia}

\section{PONTOS FORTES}

Colaboração como quesito para bonificação dos discentes.

$\mathrm{O}$ uso de um quadro em papel para ajudar na localização dos discentes facilitou a pontuação.

A solicitação aos discentes que haviam terminado seus exercícios, em tempo hábil, para sentarem ao lado de um colega com dificuldades para auxiliar nas atividades, permitiu, não só bonificar o discente por colaboração, como um aprendizado pareado.

$$
\text { PONTOS FRACOS }
$$

OBSERVACÕES

Não foi possível pontuar o quesito sugestão, pois o juiz/scoreplay não conseguiu o identificar no comportamento dos discentes.

A quantidade de slide na aula teórica e prática, não permitiu uma maior participação dos discentes.

Exemplos em códigos fontes e vetores desenhados insuficientes para instigar todos os alunos.

A planilha não penalizar de forma automática as faltas dos discentes.

Podemos identificar como pontos fortes a colaboração como quesito de bonificação, pois permitiu com que os discentes melhor se dispusessem para auxiliar os colegas e viabilizou aprendizagem por pares; uso de um quadro em papel para identificar onde os discentes estão em sala, facilitando para o scoreplay bonificar e pontuar os discentes. Os pontos fracos encontrados foram: o quesito sugestão para a bonificação, não sendo possível identificar; a quantidade de slides da aula teórica e prática, que não foi suficiente para gerar participação dos discentes; e o fato da planilha não penalizar automaticamente a falta.

$\mathrm{Na}$ análise dos pontos fracos foi possível identificar como possíveis melhorias para a próxima aula teórica e prática: obter e usar em sala de aula mais exemplos de códigos fontes e estrutura de dados homogêneos desenhados para o momento teórico da aula, com a finalidade de gerar a participação dos alunos; e o uso de função no software Microsoft Excel com o intuito de penalizar as faltas de maneira automática, por consequência gerar uma nova versão da planilha. Bem como, nas nossas observações precisamos acrescentar ao tempo de aula 5 minutos com o intuito de disponibilizar tempo para os alunos finalizarem as atividades. O Quadro 2 apresenta a matriz SWOT adaptada para o segundo dia de aula teórica e prática.

\section{Quadro 2. Matriz SWOT adaptada: ATP segundo dia}

\section{PONTOS FORTES}

Aluno bonificar por sugestão caso ele desenvolvesse um código com mais funcionalidades disponíveis que o solicitado pela questão.

Uso do pincel e o quadro branco como recurso no ensino, pois permitiu maior participação dos alunos em aula.

\section{PONTOS FRACOS}

A ocorrência de slides com erros.

Uso do pincel e o quadro branco durante a apresentação do conceito, pois o maior tempo da aula foi utilizado para apresentação da teoria.

Planilha não programada para permitir ao scoreplay anotar todas as bonificações do discente, pois quebraria a regra estabelecida do máximo de bonificações por quesito.

\section{MELHORIAS}

Verificar a corretude dos slides aplicados em sala. Elaborar slides com maior quantidade de exemplos para explicar o conceito de matriz e suas aplicações.

Alterar a planilha para a conversão em recurso estrela limitar e permitir ao scoreplay pontuar todos os comportamentos previstos como bonificações em sala de aula.

\section{OBSERVACÕES}

O tempo de aula foi acrescido de dez minutos para que alguns discentes pudessem finalizar os exercícios propostos.

Foi disponibilizada a versão 3 da planilha gamificada com as alterações necessárias para o scoreplay. 
No segundo dia de aula teórica e prática (vide Quadro 2), os pontos fortes apontados foram: o quesito sugestão ser utilizado para bonificar os discentes que desenvolviam um código com mais funcionalidades que o solicitado pela questão, como exemplo uma questão solicitava apresentar o resultado de uma operação com matriz e alguns alunos codificaram para que o resultado fosse disponibilizado em formato matricial; o uso do pincel e quadro branco para desenhar formatos de matrizes e formular questionamento aos discente como forma de instigar a participação dos mesmos. Como pontos fracos, registramos: a ocorrência de erro nos slides; uso do pincel e quadro durante a apresentação, pois fez com que a aula estivesse mais centrada na teoria, o que impossibilitou a alguns discentes terminarem a lista de desafios, determinada para o dia; o fato da planilha não estar programada para o scoreplay registrar todos os comportamentos bonificáveis adotados pelos discentes em sala de aula.

As melhorias para os próximos usos e versão do framework gamificado foram: verificar a corretude dos slides aplicados em sala; elaborar mais slides com exemplos e aplicações de matriz, com o intuito de gerar participação; alterar a planilha para a aba responsável pela conversão em recurso estrela limitar as bonificações e penalidade ao estabelecido na regra do plano de ensino. Nesse dia tivemos um acréscimo de 10 minutos ao tempo de aula para os discentes tentarem concluir a atividade e a terceira versão da planilha foi disponibilizada para o scoreplay com as alterações registradas na primeira aula teórica e prática.

Quanto às aulas teóricas e práticas, de maneira geral, os discentes participaram ativamente a partir do estímulo feito pelo docente e monitores da disciplina no momento da explicação, por meio de perguntas abertas sobre o conteúdo. Além disso, foi possível coletar dos discentes durante a aula de feedback, as seguintes informações: (i) o método adotado para a explicação estava compreensível; (ii) as questões estavam com um nível de dificuldade bom; (iii) era possível participar dentro da aula; (iv) era preciso trazer mais exemplos.

Referente ao DOJO Randori foram realizadas várias adaptações com o intuito de aprimorar a experiencia de ensino e aprendizado para os discentes. $\mathrm{O}$ primeiro formato de execução teve sua avaliação descrita no Quadro 3.

\section{Quadro 3. Matriz SWOT adaptada: DOJO Randori primeira implementação}

PONTOS FORTES MELHORIAS

Discentes desenvolveram o código em papel e utilizaram quando estavam como piloto ou copiloto na prática.

Colaboração entre membros da plateia para resolução das funcionalidades.

Melhorar a preparação da aula.

Formular uma questão aberta para ser resolvida.

Retirar o papel do copiloto e permitir plateia interagir com o piloto após 3 minutos de sua codificação.

Reforçar o papel do piloto para os discentes.

Para uma próxima versão ou uso do framework colocar no papel do piloto e copiloto o monitor e o professor.

Pontuação por colaboração apenas quando o conhecimento for difundido para a plateia inteira.

Adequar fontes de exibição do software Pascalzim para apresentação datashow.

Disponibilizar em papel impresso a questão ou questões trabalhadas na prática para todos os discentes.

\section{PONTOS FRACOS}

Durante as informações iniciais da prática falou uma melhor explicação sobre o fluxo programar-testar.

Pouca participação dos discentes no decorrer da prática.

Questões estruturadas não possibilitam uma maior quantidade de participações dos estudantes.

A função de copiloto não funcionou como o esperado.

Poucos estudantes na função de piloto interagiam com os copilotos para narrarem o desenvolvimento da solução.

Discentes que normalmente participavam nas aulas, não participaram interagindo com o piloto e copilo.

Houve a necessidade de indicar alguns discentes para

\section{OBSERVACÕES}

A aula terminou com dez minutos de antecedência.

or


realizar a prática.

Houve a ocorrência de grupos de discentes buscando soluções entre si, sem compartilhar com os demais colegas.

Faltou o exercício impresso para alguns discentes.

A linguagem de programação Pascal tem pouca possibilidade de isolamento de código.

As fontes de saída do software Pascalzim através do projetor não estavam visíveis para a maioria da plateia.

Observamos como pontos fortes: a escrita no papel pelos discentes dos códigos desenvolvidos como proposição para a resolução da questão, enquanto estavam na posição de plateia para utilizarem quando assumiam a posição de piloto e copiloto; e a colaboração entre discentes para a resolução dos problemas propostos.

Os pontos negativos para esse dia de prática foram: não explicar sobre o fluxo programartestar, o qual consiste no desenvolvimento de pequenas funcionalidades e logo após a realização do teste; pouca participação dos discentes no decorrer da prática, em geral o ambiente de DOJO solicita uma abordagem participativa das pessoas envolvidas, porém os alunos tinham pouca interação com quem estava no papel do piloto e copiloto; questões estruturadas não estimulam a participação dos alunos, uma vez que o comando indica o caminho a ser tomado para a solução do problema, por consequência deduzimos ser um dos motivos para a pouca participação dos personagens envolvidos; a função de copiloto não funcionou como o esperado, pois no decorrer da prática os discentes que estavam no papel de piloto não informavam os próximos passos para que o copiloto conseguisse auxiliar e por consequência narrar para a plateia; algumas pessoas tiveram que ser indicadas para a realização da prática; houve a formação de pequenos grupos, os quais buscavam a solução entre si e não compartilhavam com os outros integrantes da plateia; os papéis com os desafios para serem desenvolvidos foram distribuídos para grupos de discentes, porém consideramos para um próximo uso a necessidade de disponibilização de uma impressão por discente; a linguagem de programação Pascal tem pouco isolamento de código, e por consequência dificulta mas não impossibilita o fluxo programar-testar planejado para atividade; a fonte de saída do programa Pascalzim não estava disponível para toda a plateia.

Como foi possível analisar, a prática não se configurou bem para o processo de ensino e aprendizagem, então, adotamos como pontos de melhoria para o segundo dia de prática: foi preparada a aula e nesse processo olhou-se para todas as variáveis envolvidas, inclusive a impressão de cópias das questões para todos os participantes, e a fonte de saída do Pascalzim em relação à apresentação via Datashow; formulou-se uma questão aberta, para que a turma conseguisse pensar em uma solução através de estrutura de dados homogêneas; foi retirado o papel do copiloto e permitida a interação com a plateia do piloto após 3 minutos de análise e codificação pessoal da questão; reforçar a explicação sobre o papel de piloto, e agora com a prerrogativa dele narrar para a plateia o seu desenvolvimento; só bonificar colaboração quando a solução proposta for repassada para a plateia como um todo e não em grupos isolados na plateia. Nesse dia a aula finalizou com 10 minutos de antecedência.

O segundo dia da prática do DOJO já com as melhorias identificadas, teve sua análise definida no Quadro 4. Constatamos que, a partir das mudanças realizadas, a prática funcionou. Além disso, como pontos fortes: discentes participaram mais que no primeiro dia, em decorrência dos dados registrados sobre bonificação e penalidades; a prática foi divertida, observamos que os discentes estavam se divertindo programando; o comando e o apoio do professor na atividade estimulava os discentes para a participação dentro da prática; a questão aberta permitiu com que vários discentes fizessem melhorias e alterações no código, bem como um aluno foi ao quadro para apresentar o pensamento dele adotado para a resolução; discentes se envolveram, ou seja, estavam dispostos a finalizar o programa em aula, vale o destaque para os que tiveram participação voluntária. Quanto os pontos fracos identificamos: quesito sugestão não foi possível bonificar; a questão aberta impossibilitou a participação de todos os discentes, bem como 
conseguirem cada um desenvolver uma funcionalidade; a linguagem de programação adotada, que no caso é o Pascal, tem pouco isolamento de código; os discentes não conseguiam visualizar possibilidades de teste na questão.

\section{Quadro 4 - Matriz SWOT adaptada: DOJO Randori segundo dia}

\section{PONTOS FORTES}

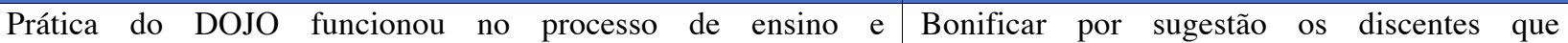
aprendizagem de Algoritmos.

Discentes participaram mais do que no primeiro dia da prática.

Houve maior colaboração entre os discentes.

Um aluno foi ao quadro para explicar um formato de solução.

A turma estava envolvida na prática, colaborou para o bom andamento e finalizar a questão.

A prática foi divertida.

Comando e apoio do professor na atividade.

A questão aberta proporcionou melhoria e alteração de código

Os discentes se sentiram motivados a finalizar o programa.

Pascalzim com fontes de saída visíveis para toda a plateia. enviarem via plataforma Moodle até uma data estabelecida outras formas de solução para a questão trabalhada.

Utilizar uma questão semiestruturada para o desenvolvimento da prática.

Quando os discentes não adotarem postura voluntária para a prática, indicar mesclando discentes com bom desempenho nas atividades com os outros.

Explicar melhor o sentido e uso do baby step em algoritmos.

Utilizar unicamente o código desenvolvido para pontuar.

Empregar o uso de bonificação para os papeis adotados pelos discentes, no caso da prática DOJO: piloto, copiloto e plateia.

PONTOS FRACOS OBSERVAÇÕES

Durante a prática não foi possível observar como pontuar sugestão.

Questão aberta inibiu alguns alunos de participarem e não possibilitou uma sequência de funcionalidades programadas.

Linguagem de programação Pascal tem pouco isolamento de código.

Discentes não conseguiam visualizar possibilidades de teste para as funcionalidades codificadas como solução para a questão.

Para o segundo dia analisamos os dados e propomos como melhorias: a bonificação por sugestão ser através do envio de novas formas de resolução da questão desenvolvida no conjunto da turma; elaborar uma questão semiestruturada para o próxima prática de DOJO; disponibilizar o monitor para auxiliar os discentes com sugestão para gerar o fluxo programar-testar; explicar melhor sobre o fluxo programar-testar com dois exemplos desenvolvidos com eles; adotar para o próximo uso ou versão do framework a bonificação pela função dos papéis e não pontuação, bem como pontuar unicamente o código desenvolvido pelos discentes. Portanto, de maneira geral, com as mudanças adotadas, observamos que a prática DOJO funciona para o ensino de algoritmos e aprendizagem de algoritmos.

\section{Quadro 5 - Matriz SWOT adaptada: Prática LAB}

\section{PONTOS FORTES \\ MELHORIAS}

Uso da prática de coaching.

Os alunos resolverem as questões propostas em duplas.

Sorteio dos pares em sala de aula, através de uma ferramenta online.

Proibir o acesso à internet .

Equilibrar o nível de dificuldade das questões na prática com o de aprendizado da turma.

Uso da bonificação por: (i) interação entre as duplas; (ii) narrar para o colega de dupla o código desenvolvido; e (iii) trocar durante a prática o papel de piloto e copiloto nas duplas.

\section{PONTOS FRACOS}

\section{OBSER VAÇÕES}

Questões com o nível de dificuldade maior que o de aprendizado da turma.

Não foi bonificado a interação entre as duplas na prática. Não foi possível observar narração dos códigos desenvolvidos e troca de função nas duplas formadas.

Permitido a prática de coaching.

Durante a prática foi possível observar duas funções nas duplas: (i) piloto, estava no computador e programava a solução; e (ii) copiloto, estava acompanhando o desenvolvimento do código e propunha melhorias.

No início da prática um grupo estava com três discentes. Após 10 minutos foi desfeito para formar duas duplas, pois um outro discente chegou. 
A avaliação da prática LAB está disposta no Quadro 5. Dentre os pontos positivos destacamos: a prática de coaching, no momento em que os outros personagens da gamificação auxiliavam os jogadores com dicas para a resolução dos desafios; a resolução dos desafios ocorrerem em duplas, pois permitiu no decorrer da prática uma análise do problema computacional bem como sua resolução por dois estudantes; sorteio online para a formação das duplas através de uma ferramenta online, com o intuito de diminuir o viés; proibir o acesso a internet, permitindo aos discentes focarem em desenvolver estratégias de resolução dos problemas. Como pontos fracos temos: as questões desafio com nível de dificuldade muito elevado, o fato também foi retratado pelos discentes também na aula de feedback; não foi bonificado o comportamento dos discentes no decorrer da prática, bem como os discentes que iniciaram com o comando do computador finalizaram a prática.

Como melhorias da prática de $\mathrm{LAB}$, descrevemos: equivaler às questões da prática com o nível de aprendizado da turma; bonificar o comportamento dos alunos na prática em relação (i) a interação entre as duplas, (ii) a narração para o colega de dupla do código desenvolvido e (iii) a troca durante a prática do papel de piloto e copiloto nas duplas

$\mathrm{Na}$ aula de feedback sobre a prática LAB, os discentes levantaram como pontos de melhoria as questões trabalhadas em sala de aula aumentarem gradativamente o nível de dificuldade na sequência de exibição. Em relação à lista de exercício para casa, os alunos informaram a necessidade de um tempo dentro da aula teórica e prática para discutir como resolver cada uma das questões, com possibilidades de dicas.

Em relação aos cenários de aprendizagem adotados, no caso o DOJO Randori e o LAB, os discentes durante a aula de feedback afirmaram ser uma experiência positiva para o aprendizado dentro da disciplina. Vale ressaltar que eles solicitaram que tais práticas pudessem ser adotadas em todos os conteúdos trabalhados na disciplina.

No caso do teste teórico e da aula de feedback não foram elaboradas matrizes SWOT adaptadas, mas coletamos informações sobre elas. A primeira prática permitiu a avaliação de desempenho individual dos discentes após as práticas gamificadas, e tem seu formato regido de como o professor já trabalhava esse elemento em sala. A segunda foi uma experiência diferencial para os discentes em que apontaram sugestões e reafirmaram o uso das novas práticas para o ensino e aprendizado de Algoritmos.

De maneira geral, sobre as metodologias utilizadas no experimento, os discentes afirmaram que a utilização de uma sala de aula gamificada para o ensino do conteúdo de estrutura de dados na disciplina de Algoritmos foi muito válida. Por meio dela os discentes tiveram a visão teórica e prática necessária do assunto. Vale ressaltar que todos os pontos levantados pelos personagens da gamificação foram amplamente discutidos e sistematizados neste artigo com a finalidade de aprimorar o framework gamificado para o processo de ensino e aprendizagem na disciplina Algoritmos.

\subsection{Discussão e Resultados Quantitativos}

Os dados quantitativos apoiam os qualitativos a fim de avaliar o framework gamificado para os próximos usos e versão do produto. Nessa discussão, a análise foi realizada em relação ao conteúdo, dados relacionados à atribuição de pontos e avatar, resultados e discussão em relação ao comportamento, informações relativas ao elemento bônus e ao recurso estrela adquiridos pelos discentes, e o elemento medalha, prêmio para os discentes melhores colocados.

O score de gamificação é formado pelo desempenho do discente em relação ao conteúdo. Os discentes respondiam as listas de desafio ganhavam pontos dentro da estrutura gamificada (vide Figura 1). A gamificação possibilitou uma progressão de aprendizagem no conteúdo da disciplina, como se percebe nos alunos 12 e 20 . Os discentes com o desempenho considerado não muito satisfatório, no caso, receberam o avatar Amador e Aprendiz, foram pessoas não presentes em sala de aula e que não procuraram a professora da disciplina e nem o responsável pela gamificação para suprir essa situação. 


\begin{tabular}{|c|c|c|c|c|c|c|c|c|c|}
\hline 4 & A & B & C & D & $E$ & $\mathrm{~F}$ & G & $\mathrm{H}$ & I \\
\hline 1 & Membro & Lista Exercicio 01 & Lista Exercicio 02 & Lista Exercicio Casa & Dojo & LAB & Prova Teórica & TOTAL & AVATAR FINAL \\
\hline 2 & Aluno 01 & 0 & 75 & 0 & 66,75 & 0 & 0 & \begin{tabular}{|l|}
141,75 \\
\end{tabular} & AMADOR \\
\hline 3 & Aluno 02 & 100 & 75 & 0 & 143,75 & 85 & 11,25 & 415 & AMADOR \\
\hline 4 & Aluno 03 & 100 & 50 & 0 & 193,75 & 155 & 95 & 593,75 & APRENDIZ \\
\hline 5 & Aluno 04 & 100 & 100 & 99 & 177,5 & 200 & 290 & 966,5 & ANALISTA \\
\hline 6 & Aluno 05 & 100 & 100 & 86 & 193,75 & 198 & 300 & 977,75 & ANALISTA \\
\hline 7 & Aluno 06 & 100 & 100 & 67 & 198,5 & 180 & 300 & 945,5 & ANALISTA \\
\hline 8 & Aluno 07 & 100 & 100 & 86 & 197 & 140 & 275 & 898 & PROGRAMADOR \\
\hline 9 & Aluno 08 & 100 & 100 & 80 & 193,75 & 0 & 275 & 748,75 & PROGRAMADOR \\
\hline 10 & Aluno 09 & 100 & 62,5 & 0 & 177,75 & 170 & 55 & 565,25 & APRENDIZ \\
\hline 11. & Aluno 10 & 100 & 75 & 0 & 193,75 & 50 & 185 & 603,75 & APRENDIZ \\
\hline 12 . & Aluno 11 & 100 & 100 & 58 & 143,75 & 150 & 300 & 851,75 & PROGRAMADOR \\
\hline 13 & Aluno 12 & 100 & 75 & 88 & 195,5 & 200 & 300 & 958,5 & ANALISTA \\
\hline 14. & Aluno 13 & 100 & 100 & 68 & 193,75 & 198 & 275 & 934,75 & ANALISTA \\
\hline 15 & Aluno 14 & 75 & 75 & 0 & 112,75 & 0 & 275 & 537,75 & APRENDIZ \\
\hline 16 & Aluno 15 & 75 & 75 & 0 & 127,75 & 145 & 245 & 667,75 & APRENDIZ \\
\hline 17 & Aluno 16 & 100 & 62,5 & 0 & 183,75 & 85 & 75 & 506,25 & APRENDIZ \\
\hline 18 & Aluno 17 & 0 & 50 & 0 & 66,75 & 0 & 0 & 116,75 & AMADOR \\
\hline 19 & Aluno 18 & 75 & 75 & 0 & 66,75 & 50 & 155 & 421,75 & AMADOR \\
\hline 20 & Aluno 19 & 100 & 0 & 0 & 193,75 & 140 & 260 & 693,75 & APRENDIZ \\
\hline 21 & Aluno 20 & 100 & 0 & 24 & 162,75 & 70 & 147,5 & 504,25 & APRENDIZ \\
\hline
\end{tabular}

Figura 1. Scoreplay da gamificação

Os resultados obtidos no primeiro dia da aula teórica e prática estão na Figura 2. Observamos que a maioria dos discentes presentes em sala de aula conseguiu finalizar a atividade em sala, exceto os Alunos 14, 15 e 18. Nesse dia o elemento de colaboração destacou-se, favorecendo a interação entre os discentes, que se ajudaram para finalizar as questões.

\begin{tabular}{|c|c|c|c|c|c|c|c|}
\hline \multirow{3}{*}{$\begin{array}{l}1 \\
2\end{array}$} & \multirow{3}{*}{ Membros } & B & c & D & E & $\mathrm{F}$ & G \\
\hline & & \multicolumn{4}{|c|}{ Resultado Pontuação Aula Teórica e Prática - $1^{\circ}$ Dia } & \multirow{2}{*}{ TOTAL } & \multirow{2}{*}{ AVATAR DIA } \\
\hline & & $1^{\circ}$ Questão & $2^{\circ}$ Questão & $3^{\circ}$ Questão & $4^{\circ}$ Questão & & \\
\hline 3 & Aluno 01 & 0 & 0 & 0 & 0 & 0 & AMADOR \\
\hline 4 & Aluno 02 & 1 & 1 & 1 & 1 & 100 & ANALISTA \\
\hline 5 & Aluno 03 & 1 & 1 & 1 & 1 & 100 & ANALISTA \\
\hline 6 & Aluno 04 & 1 & 1 & 1 & 1 & 100 & ANALISTA \\
\hline 7 & Aluno 05 & 1 & 1 & 1 & 1 & 100 & ANALISTA \\
\hline 8 & Aluno 06 & 1 & 1 & 1 & 1 & 100 & ANALISTA \\
\hline 9 & Aluno 07 & 1 & 1 & 1 & 1 & 100 & ANALISTA \\
\hline 10 & Aluno 08 & 1 & 1 & 1 & 1 & 100 & ANALISTA \\
\hline 11 & Aluno 09 & 1 & 1 & 1 & 1 & 100 & ANALISTA \\
\hline 12 & Aluno 10 & 1 & 1 & 1 & 1 & 100 & ANALISTA \\
\hline 13 & Aluno 11 & 1 & 1 & 1 & 1 & 100 & ANALISTA \\
\hline 14 & Aluno 12 & 1 & 1 & 1 & 1 & 100 & ANALISTA \\
\hline 15 & Aluno 13 & 1 & 1 & 1 & 1 & 100 & ANALISTA \\
\hline 16 & Aluno 14 & 1 & 1 & 1 & 0 & 75 & PROGRAMADOR \\
\hline 17 & Aluno 15 & 1 & 1 & 1 & 0 & 75 & PROGRAMADOR \\
\hline 18 & Aluno 16 & 1 & 1 & 1 & 1 & 100 & ANALISTA \\
\hline 19 & Aluno 17 & 0 & 0 & 0 & 0 & 0 & AMADOR \\
\hline 20 & Aluno 18 & 1 & 1 & 1 & 0 & 75 & PROGRAMADOR \\
\hline 21 & Aluno 19 & 1 & 1 & 1 & 1 & 100 & ANALISTA \\
\hline 22 & Aluno 20 & 1 & 1 & 1 & 1 & 100 & ANALISTA \\
\hline
\end{tabular}

Figura 2. Resultado da Aula Teórica e Prática primeiro dia

No segundo dia de aula teórica e prática temos resultados apresentados na Figura 3. O preenchimento 0,5 deu-se após uma conversa em turma com a professora e com o responsável pela gamificação, para pontuar o discente quando não completava inteiramente o que era solicitado no comando da questão, a pontuação atribuída era de 12,5 pontos. Por motivo da planilha estar programada para preenchimento automático do scoreplay. Nesse dia também $50 \%$ da turma não conseguiu finalizar toda a atividade, um dos pontos para esse acontecimento foi registrado no SWOT diário da atividade, Quadro 2.

A prática de DOJO Randori aconteceu em dois dias e o resultado das pontuações pode ser visto na Figura 4. Nessa prática tivemos alterações na medida do desenvolvimento da prática, os preenchimentos decimais, pois não atendiam inteiramente o requisito, e como a planilha estava automatizada para o preenchimento de 0 ou 1, adotamos como solução essa prática. Após os resultados apresentados e a forma como a prática é descrita na literatura como melhoria para a 
próxima execução do framework gamificado, decidimos pontuar unicamente pelo código desenvolvido e remover os outros critérios que serão devidamente bonificados à medida que for desenvolvendo a prática.

\begin{tabular}{|c|c|c|c|c|c|c|c|}
\hline 23 & \multirow{2}{*}{ Membros } & \multicolumn{4}{|c|}{ Resultado Pontuação Aula Teórica e Prática - $2^{\circ}$ Dia } & \multirow{2}{*}{ TOTAL } & \multirow{2}{*}{ AVATAR DIA } \\
\hline 24 & & $1^{\circ}$ Questão & $2^{\circ}$ Questão & $3^{\circ}$ Questão & $4^{\circ}$ Questão & & \\
\hline 25 & Aluno 01 & 1 & 1 & 1 & 0 & 75 & PROGRAMADOR \\
\hline 26 & Aluno 02 & 1 & 1 & 1 & 0 & 75 & PROGRAMADOR \\
\hline 27 & Aluno 03 & 1 & 1 & 0 & 0 & 50 & AMADOR \\
\hline 28 & Aluno 04 & 1 & 1 & 1 & 1 & 100 & ANALISTA \\
\hline 29 & Aluno 05 & 1 & 1 & 1 & 1 & 100 & ANALISTA \\
\hline 30 & Aluno 06 & 1 & 1 & 1 & 1 & 100 & ANALISTA \\
\hline 31 & Aluno 07 & 1 & 1 & 1 & 1 & 100 & ANALISTA \\
\hline 32 & Aluno 08 & 1 & 1 & 1 & 1 & 100 & ANALISTA \\
\hline 33 & Aluno 09 & 1 & 1 & 0,5 & 0 & 62,5 & APRENDIZ \\
\hline 34 & Aluno 10 & 1 & 1 & 1 & 0 & 75 & PROGRAMADOR \\
\hline 35 & Aluno 11 & 1 & 1 & 1 & 1 & 100 & ANALISTA \\
\hline 36 & Aluno 12 & 1 & 1 & 1 & 0 & 75 & PROGRAMADOR \\
\hline 37 & Aluno 13 & 1 & 1 & 1 & 1 & 100 & ANALISTA \\
\hline 38 & Aluno 14 & 1 & 1 & 1 & 0 & 75 & PROGRAMADOR \\
\hline 39 & Aluno 15 & 1 & 1 & 1 & 0 & 75 & PROGRAMADOR \\
\hline 40 & Aluno 16 & 1 & 1 & 0,5 & 0 & 62,5 & APRENDIZ \\
\hline 41 & Aluno 17 & 1 & 1 & 0 & 0 & 50 & AMADOR \\
\hline 42 & Aluno 18 & 1 & 1 & 1 & 0 & 75 & PROGRAMADOR \\
\hline 43 & Aluno 19 & 0 & 0 & 0 & 0 & 0 & AMADOR \\
\hline 44 & Aluno 20 & 0 & 0 & 0 & 0 & 0 & AMADOR \\
\hline
\end{tabular}

Figura 3. Resultado da Aula Teórica e Prática segundo dia

\begin{tabular}{|c|c|c|c|c|c|c|c|}
\hline \multirow{3}{*}{$\begin{array}{l}\frac{4}{1} \\
2\end{array}$} & A & $B$ & c & D & E & $\mathrm{F}$ & G \\
\hline & \multirow{2}{*}{ Membros } & \multicolumn{4}{|c|}{\begin{tabular}{|c|c|c|} 
& DOJO \\
\end{tabular}} & \multirow{2}{*}{ TOTAL } & \multirow{2}{*}{ AVATAR } \\
\hline & & Uma funcionalidade concluída & Utilizou of fluxo Programar-Testa & Narrou a programaçã & Nota geral das questôes & & \\
\hline 3 & Aluno 01 & 0,2 & 0,3 & 0,1 & 43,75 & 66,75 & AMADOR \\
\hline 4 & Aluno 02 & 1 & 1 & 0,5 & 43,75 & 143,75 & APRENDIZ \\
\hline 5 & Aluno 03 & 1 & 1 & 1 & 43,75 & 193,75 & ANALISTA \\
\hline 6 & Aluno 04 & 1 & 0,3 & 1 & 48,5 & 177,5 & PROGRAMADOR \\
\hline 7 & Aluno 05 & 1 & 1 & 1 & 43,75 & 193,75 & ANALISTA \\
\hline 8 & Aluno 06 & 1 & 1 & 1 & 48,5 & 198,5 & ANALISTA \\
\hline 9 & Aluno 07 & 1 & 1 & 1 & 47 & 197 & ANALISTA \\
\hline 10 & Aluno 08 & 1 & 1 & 1 & 43,75 & 193,75 & ANALISTA \\
\hline 11 & Aluno 09 & 0,2 & 1 & 1 & 43,75 & 177,75 & PROGRAMADOR \\
\hline 12 & Aluno 10 & 1 & 1 & 1 & 43,75 & 193,75 & ANALISTA \\
\hline 13 & Aluno 11 & 1 & 1 & 0,5 & 43,75 & 143,75 & APRENDIZ \\
\hline 14 & Aluno 12 & 1 & 1 & 1 & 45,5 & 195,5 & ANALISTA \\
\hline 15 & Aluno 13 & 1 & 1 & 1 & 43,75 & 193,75 & ANALISTA \\
\hline 16 & Aluno 14 & 0,5 & 0,3 & 0,5 & 43,75 & 112,75 & AMADOR \\
\hline 17 & Aluno 15 & 0,2 & 1 & 0,5 & 43,75 & 127,75 & APRENDIZ \\
\hline 18 & Aluno 16 & 0,5 & 1 & 1 & 43,75 & 183,75 & ANALISTA \\
\hline 19 & Aluno 17 & 0,2 & 0,3 & 0,1 & 43,75 & 66,75 & AMADOR \\
\hline 20 & Aluno 18 & 0,2 & 0,3 & 0,1 & 43,75 & 66,75 & AMADOR \\
\hline 21 & Aluno 19 & 1 & 1 & 1 & 43,75 & 193,75 & ANALISTA \\
\hline 22 & Aluno 20 & 0,5 & 0,3 & 1 & 43,75 & 162,75 & PROGRAMADOR \\
\hline
\end{tabular}

Figura 4. Resultados prática DOJO Randori

No framework gamificado, a lista de exercício para casa é pontuada em conjunto com a prática LAB e seus resultados estão apresentados na Figura 5. O recurso teve adesão de 50\%, e nenhum discente conseguiu alcançar os 100 pontos destinados à lista. Sobre essa situação, durante a aula de feedback os discentes afirmaram que a lista estava com um nível de dificuldade muito alto, por isso nem tentaram entregar. Entretanto, informaram a necessidade de um tempo na aula teórica e prática para dicas na resolução do recurso.

O resultado da prática LAB está apresentado na planilha da Figura 6. O avatar analista foi concedido para apenas 3 discentes, são eles 04,05 e 12 . O fato colabora com a informação de que as questões solicitadas estavam em um nível de dificuldade maior que o de aprendizado da turma, vide SWOT no Quadro 5, confirmado através da aula de feedback. Os discentes apontaram que as questões desafios do dia estavam com um nível muito elevado para a turma. 


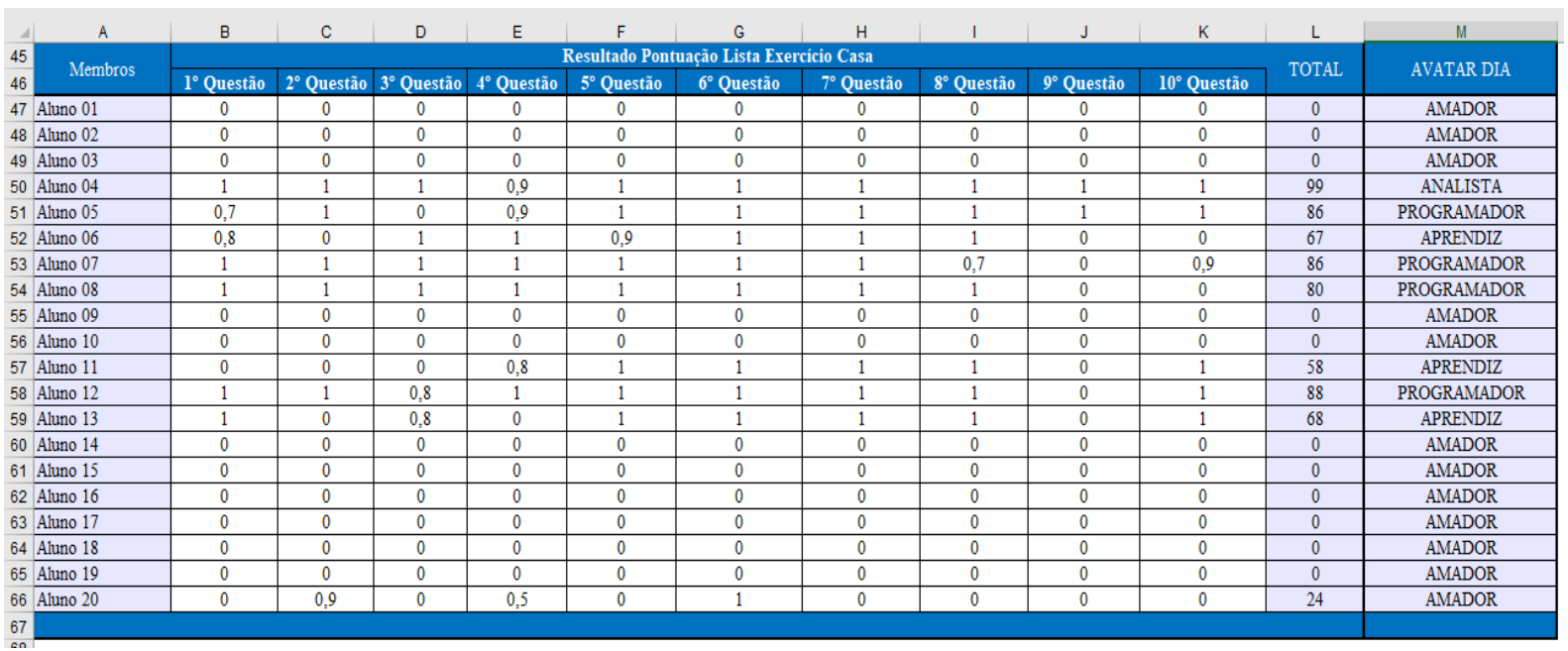

Figura 5. Resultado Lista de Exercício para Casa

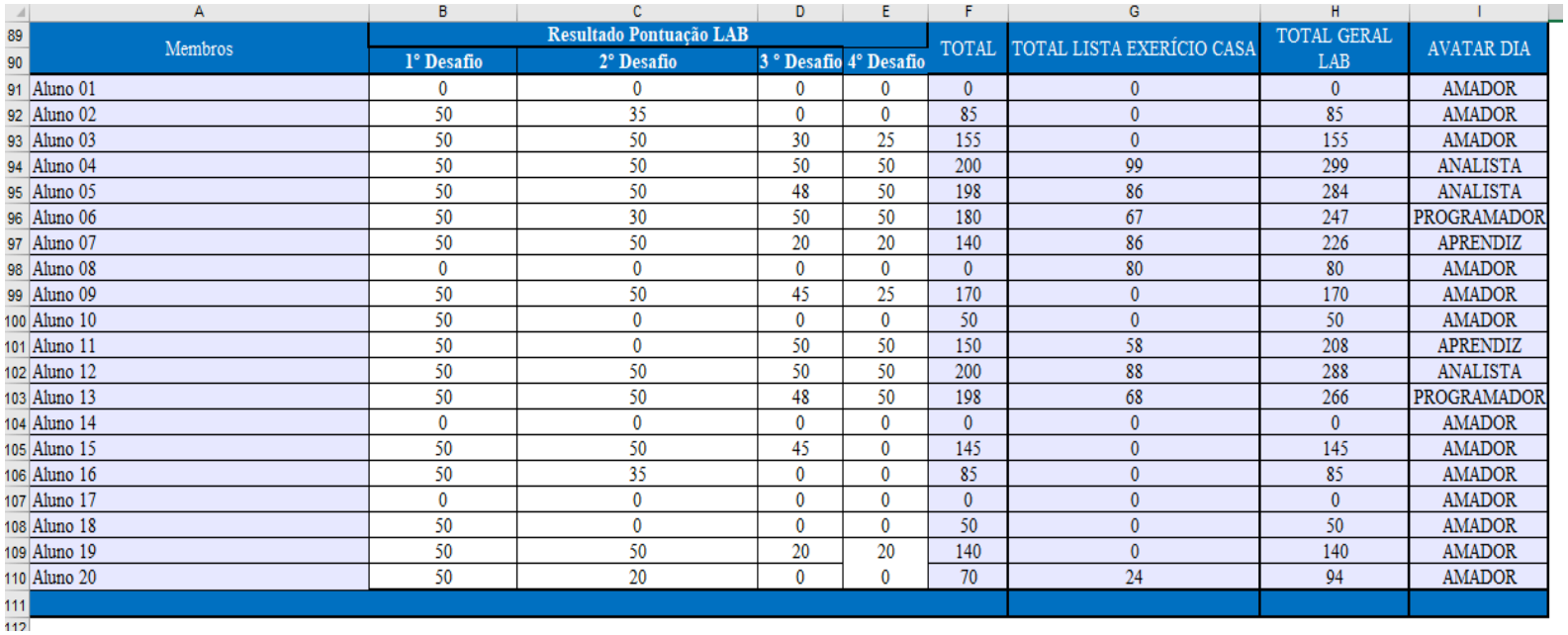

Figura 6. Resultado prática Laboratório de Programação

O discente na prática LAB pontuava em 2 quesitos por questão: (i) tentativa, 20 pontos, preenchimento 0 ou 1 na coluna Atividade Concluída; e (ii) corretude do código, até 30 pontos, preenchimento com o valor de pontos atribuído. A planilha somava o valor para as duas colunas e apresentava no total de maneira automática.

$\mathrm{Na}$ prática do LAB foi permitido aos alunos enviarem resoluções para as questões propostas até 3 dias após a prática, via plataforma Moodle. O envio possibilitaria a alteração da nota do desafio, após análise do código pelo master, mas não pontuaria por tentativa. Sobre essa nova entrega, consideramos: (i) apenas o aluno 03 teve sua nota alterada; e (ii) o aluno 06 apresentou uma nova forma de resolução para o problema proposto.

A regra de extensão do prazo para o envio das atividades não observamos como algo válido para os próximos usos ou versões do framework gamificado.

A Figura 7 apresenta o resultado da atividade avaliativa individual realizada dentro do framework, o teste teórico. 9 dos 20 alunos conseguiram chegar ao avatar analista e dois ao programador. Essa informação indica o sucesso de se trabalhar a gamificação no processo de ensino e aprendizagem de Algoritmos. Mais de 50\% dos discentes obtiveram um desempenho de bom para excelente em uma atividade avaliativa já usada na abordagem tradicional da disciplina. Além disso, o Aluno 17, que tinha dificuldade na disciplina, conseguiu escrever um algoritmo correto e completo para a solução de um problema computacional, no caso a $2^{\circ}$ questão.

$\mathrm{Na}$ correção do teste teórico foi adotada a mesma estrutura adotada na prática LAB, porém com a seguinte alteração na distribuição de pontos pela tentativa: (i) montar a estrutura base do algoritmo; e (ii) codificar de maneira correta a estrutura de repetição para leitura da 
estrutura de dados. Cada quesito atribuía metade dos pontos da tentativa, preenchimento na planilha com valores de $0,0,5$ ou 1 na coluna atividade concluída. O Aluno 02 teve a atribuição de 0,5 na primeira e 1 na segunda questão. Assim, observamos que a maioria dos discentes tiveram essas duas expertises consideradas para a pontuação pela tentativa no desenvolvimento de algoritmos.

\begin{tabular}{|c|c|c|c|c|c|c|c|}
\hline \multirow{3}{*}{$\begin{array}{l}4 \\
89 \\
90\end{array}$} & A & B & c & D & $\mathrm{E}$ & $\mathrm{F}$ & G \\
\hline & \multirow{2}{*}{ Membros } & \multicolumn{4}{|c|}{ Resultado Pontuação Teste Teórico } & \multirow{2}{*}{ TOTAL } & \multirow{2}{*}{ AVATAR DIA } \\
\hline & & $1^{\circ}$ Questão & $2^{\circ}$ Questão & $3^{\circ}$ Questão & $4^{\circ}$ Questão & & \\
\hline 91 & Aluno 01 & 0 & 0 & 0 & 0 & 0 & AMADOR \\
\hline 92 & Aluno 02 & 3,75 & 7,5 & 0 & 0 & 11,25 & AMADOR \\
\hline 93 & Aluno 03 & 15 & 30 & 50 & 0 & 95 & AMADOR \\
\hline 94 & Aluno 04 & 75 & 75 & 65 & 75 & 290 & ANALISTA \\
\hline 95 & Aluno 05 & 75 & 75 & 75 & 75 & 300 & ANALISTA \\
\hline 96 & Aluno 06 & 75 & 75 & 75 & 75 & 300 & ANALISTA \\
\hline 97 & Aluno 07 & 50 & 75 & 75 & 75 & 275 & ANALISTA \\
\hline 98 & Aluno 08 & 50 & 75 & 75 & 75 & 275 & ANALISTA \\
\hline 99 & Aluno 09 & 15 & 25 & 15 & 0 & 55 & AMADOR \\
\hline 100 & Aluno 10 & 40 & 75 & 70 & 0 & 185 & AMADOR \\
\hline 101 & Aluno 11 & 75 & 75 & 75 & 75 & 300 & ANALISTA \\
\hline 102 & Aluno 12 & 75 & 75 & 75 & 75 & 300 & ANALISTA \\
\hline 103 & Aluno 13 & 50 & 75 & 75 & 75 & 275 & ANALISTA \\
\hline 104 & Aluno 14 & 50 & 75 & 75 & 75 & 275 & ANALISTA \\
\hline 105 & Aluno 15 & 40 & 75 & 55 & 75 & 245 & PROGRAMADOR \\
\hline 106 & Aluno 16 & 0 & 75 & 0 & 0 & 75 & AMADOR \\
\hline 107 & Aluno 17 & 0 & 0 & 0 & 0 & 0 & AMADOR \\
\hline 108 & Aluno 18 & 65 & 75 & 15 & 0 & 155 & AMADOR \\
\hline 109 & Aluno 19 & 45 & 75 & 75 & 65 & 260 & PROGRAMADOR \\
\hline 110 & Aluno 20 & 7,5 & 75 & 40 & 25 & 147,5 & AMADOR \\
\hline 111 & & & & & & & \\
\hline
\end{tabular}

Figura 7. Resultado do Teste teórico

Os discentes podiam ver o crescimento do seu desempenho, bem como o da turma através de uma representação visual, o ranking, apresentado na Figura 8. A representação visual permitida pelo ranking colabora para o elemento de jogo de competição e a característica de feedback, retratada na literatura e nas metodologias de coleta de dados. Nenhum dos discentes conseguiu alcançar os 1000 pontos dentro da gamificação. Porém, vários discentes aproximaramse, como é o caso do discente ganhador da medalha Power, discente 05, com 977,75.

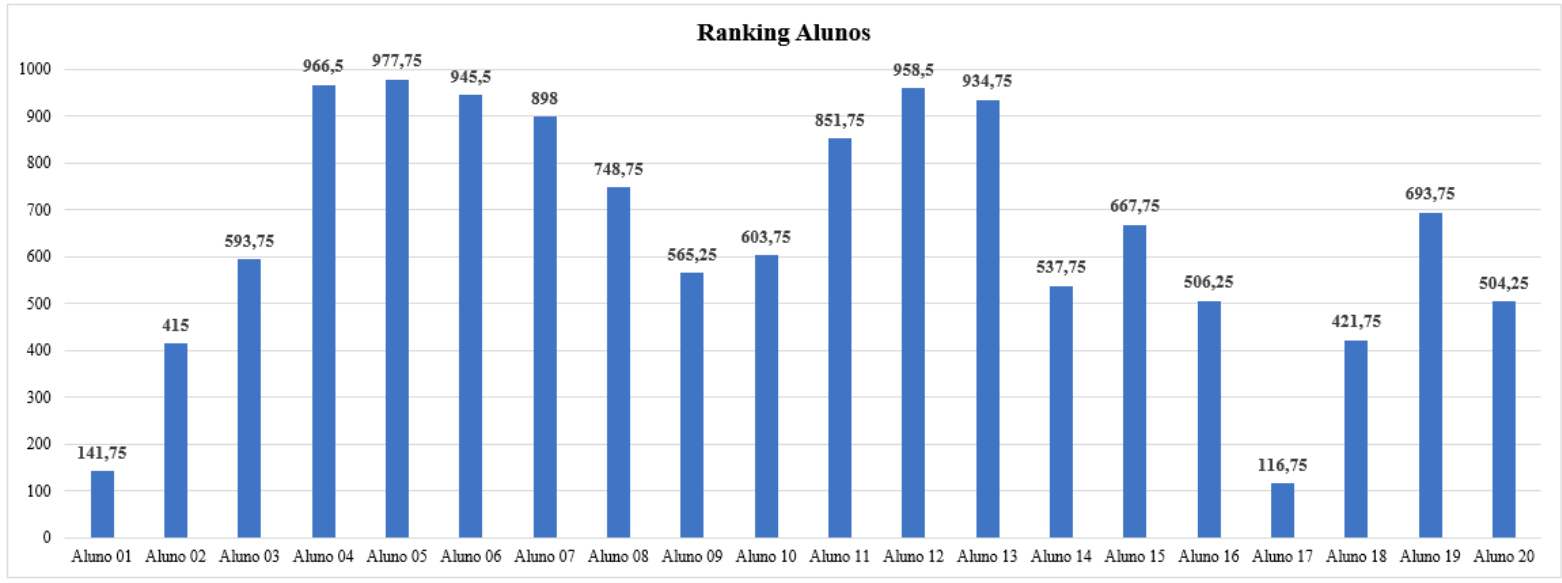

Figura 8. Ranking dos Discentes

De maneira geral o elemento pontos permitiu aos discentes um feedback positivo sobre o seu andamento dentro do conteúdo gamificado. Além disso, precisa-se: ajustar a distribuição de pontos, tais como permitir uma maior liberdade na prática do DOJO pontuando unicamente o código coletivo; e definir uma regra para a pontuação por tentativa na prática do LAB.

Os resultados sobre comportamento estavam dispostos em uma aba da planilha gamificada para os discentes. Ela tinha preenchimento automático, após o scoreplay preencher as abas de bonificações e penalidades. Nesta aba podemos visualizar o total de bônus adquirido e o total de estrelas por dia. Esse conjunto de informação estava disponível aos discentes em cada uma das aulas do framework. Esta aba foi pensada como feedback mais imediato para o discente em relação ao seu ganho de recurso estrela em todo o processo. 
Na Figura 9 temos um dado para a discussão sobre a progressão do recurso estrela em todo o processo da gamificação. A aula 4, DOJO Randori segundo dia, atingiu o maior número de alcance do recurso estrela. Na prática de feedback, aula 07, a qual imaginamos ser o dia em que mais se distribuiria estrelas, ficou empatada com a primeira aula teórica e prática, aula 01 . Então, é importante uma discussão futura de novas formas para coletar informações dos discentes sobre o framework, durante a aula de feedback.

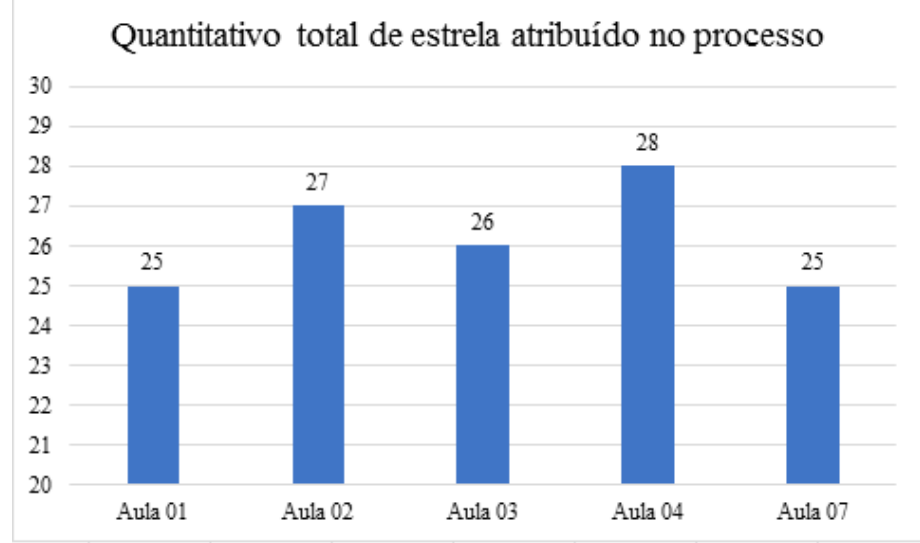

Figura 9. Quantidade de estrelas atribuídas no decorrer do processo

De uma maneira geral sobre o elemento recurso estrelas atribuídas, nenhum dos discentes conseguiu as 3 estrelas, meta diária. Podemos identificar novas formas de bonificação, ou então retirar as limitações de bonificação com o intuito de permitir aos discentes conseguirem alcançar o objetivo diário para o componente nos próximos usos do framework gamificado.

Outro elemento da gamificação utilizado com o intuito de analisar o desempenho dos discentes em relação ao conteúdo e a participação foi a medalha. Para o experimento relatado adotou-se as categorias: Power e Participativo. A primeira refere-se à quantidade de pontos que o discente tinha acumulado no decorrer da gamificação, ou seja, o desempenho (vide Figura 10). A Power subdividia-se em: ouro, prata e bronze. A segunda medalha indicava o discente com maior quantidade de estrelas, ou seja, o que mais participou no processo (vide Figura 11). A segunda medalha tinha três subdivisões, similar a Power.

\begin{tabular}{|c|c|c|c|}
\hline \multicolumn{4}{|c|}{ Medalhas - Power } \\
\hline Posição & Valor & Nome & Tipo \\
\hline $1^{\circ}$ Lugar & 977,75 & Aluno 05 & Ouro \\
\hline $2^{\circ}$ Lugar & 966,5 & Aluno 04 & Prata \\
\hline $3^{\circ}$ Lugar & 958,5 & Aluno 12 & Bronze \\
\hline
\end{tabular}

Figura 10. Medalha Power atribuída

\begin{tabular}{|c|c|c|c|}
\hline \multicolumn{4}{|c|}{ Medalhas - Participativo } \\
\hline Posição & Valor & Nome & Tipo \\
\hline $1^{\circ}$ Lugar & 10 & Aluno 12 & Ouro \\
\hline $2^{\circ}$ Lugar & 9 & EMPATE & Prata \\
\hline $3^{\circ}$ Lugar & 9 & EMPATE & Bronze \\
\hline
\end{tabular}

Figura 11. Medalha Participativo

O elemento medalha foi adicionado ao framework com o intuito de estimular a competição entre os discentes. Porém, na aula de feedback eles informaram como elemento central a colaboração. $O$ ponto de melhoria seria a disponibilização de prêmios para os primeiros lugares nas medalhas, com o intuito de um maior estímulo para os discentes.

\section{Conclusões}

O foco do trabalho foi o relato da condução de um experimento com o uso de um framework gamificado para o processo de ensino e aprendizagem de algoritmos em um curso de graduação 
na Universidade Federal do Pará. Os resultados coletados foram sistematizados e analisados em dois grupos: qualitativo e quantitativo. O primeiro grupo foi relatado através de uma matriz SWOT adaptada. O segundo grupo foi dissertado através dos dados coletados via planilha gamificada, subdivididos através de três elementos de jogos: pontos, recurso estrela e as medalhas da gamificação. As análises dos dados permitiram inferir algumas melhorias no framework. O uso da matriz SWOT adaptada permitiu uma forma de análise diferenciada do produto em relação a cada prática e melhorias tanto para um novo uso, como para nova versão. Portanto, acreditamos ser boa forma de sistematizar os dados para gerar conhecimento em relação a cada uma das práticas adotadas no processo. Outro ponto interessante que vale destaque é a aula de feedback, onde podemos através da opinião e visão dos próprios discentes aprimorar a prática docente em sala de aula.

Através da análise dos dados quantitativos e qualitativos constatamos o sucesso ao adotar um framework gamificado para o processo de ensino e aprendizagem de Algoritmos, pois permite aos discentes envolvidos: ganho de desempenho e engajamento nas atividades propostas, em especial para o conteúdo de estrutura de dados homogêneos, por ter sido adotado para avaliar a proposta. Como trabalhos futuros, pretendemos: desenvolver uma nova versão do framework gamificado; adotá-lo em outro conteúdo da disciplina Algoritmos; elaborar e gerar uma ferramenta para apoiar a condução do framework em sala de aula; e analisar as possibilidades de acessibilidade para o framework.

\section{Referências}

Baldner, P. R., Decourt, F., Neves, H. D. (2012). "Planejamento e gestão estratégica". Rio de Janeiro: Fundação Getúlio Vargas (FGV).

Bosse, Y., Gerosa, M. A. (2015). "Reprovações e Trancamentos nas Disciplinas de Introdução à Programação da Universidade de São Paulo: Um Estudo Preliminar”. In: WEI-Workshop sobre Educação em Computação, pp. 1 - 10.

Creswell, J. W. (2007). "Uma estrutura para projeto. Projeto de pesquisa: métodos qualitativo, quantitativo e misto". Porto Alegre: Artmed.

Deterding, S., Dixon, D., Khaled, R., Nacke, L. (2011). "From game design elements to gamefulness: defining gamification". In: 15th international academic MindTrek conference: Envisioning future media environments, pp. 9-15.

Dias Júnior, M., Mercado, L. (2016). "A Importância da Estratégia de Ensino por Simulação para a Disciplina de Algoritmos". In: $5^{\circ}$ CIAIQ, pp. 85 - 94.

Elgrably, I. S., Oliveira, S. R. (2018). "Gamification and Evaluation of the Use the Agile Tests in Software Quality Subjects: the Application of Experiments". In: 13th ENASE.

Luz, R. B., Neto, A. (2012). "Using Programming Dojos for Test-Driven Development Teaching". In: XXIII SBIE 2012. pp. 25-35.

Marcussi, L. D., Guedes, K., Molin Filho, R. G., Santiago Filho, R. M., Beleti Junior, C. R. (2016). "Pesquisa no ensino de algoritmos e programação nas engenharias: estudos e resultados preliminares". In: SIMEPRO.

Quaresma, J. A. S., Eliasquevici, M. K., Oliveira, S. R. B. (2018). "Um Framework Gamificado para Ensino e Aprendizagem de uma Disciplina de Algoritmos ou Equivalente". In: TISE.

Ramos, V., Freitas, M., Galimberti, M., Mariani, A. C., Wazlawick, R. (2015). "A Comparação da Realidade Mundial do Ensino de Programação para Iniciantes com a Realidade Nacional: Revisão sistemática da literatura em eventos brasileiros". In: SBIE. pp. 318 - 327.

Santos, E. D., Oliveira, S. R. (2018). "Gamificação como Ferramenta de Suporte de Apoio ao Ensino da Técnica Análise de Pontos por Função em um Turma de Pós-Graduação: Um Estudo de Caso". 15th CONTECSI.

Sociedade Brasileira de Computação (2017). . Referenciais de formação para os cursos de graduação em Computação 2017. 